\title{
Development of a Cost Effective Power Generation System: An Overview
}

\author{
Shiv Prakash Bihari ${ }^{* 1}$, Yogita Kumari ${ }^{2}$, Bhupender Sehgal ${ }^{3}$, \\ RN Chaubey ${ }^{4}$, Anmol Gupta ${ }^{5}$ \\ 1,2,3,5 Inderprastha Engineering College, Ghaziabad, Uttar Pradesh 201010, India \\ ${ }^{4}$ Krishna Institute of Engineering and Technology, Ghaziabad, Uttar Pradesh 201206, India \\ *Corresponding author, e-mail: spbiharinit@gmail.com', yogitaaryanipec@gmail.com²
}

\begin{abstract}
This paper presents an overview on development of cost effective power generation system and motivates for development of a model for hybrid system with wind to investigate the combined operation of wind with different sources to cater to wind's stochastic nature for imbalance minimization and optimal operation. Development of model for trading power in competitive electricity market and development of strategies for trading in electricity markets (wind energy and reserves markets) to investigate the effects of real time pricing tariffs on electricity market operation has been illustrated in this paper. Dynamic modelling related studies to investigate the wind generator's kinetic energy for primary frequency support using simulink and simulation studies on doubly fed induction generator to study its capability during small disturbances / fluctuations on power system have been described.
\end{abstract}

Keywords: Wind power generation system, electricity market, simulink, doubly fed induction generator

\section{Introduction}

The continued economic development and exponential population growth are driving global demand rapidly and major portion of the power demand is met by carbon-fossil based energy sources, which have limited capacities and also have adverse effects on the environment. Thus growing concern about the environment, worldwide move for deregulation of electricity and energy markets and rich developments in renewable and high efficiency technologies have led towards the growth of small environment friendly dispersed power generating units of variety of forms called distributed generation (DG). The emphasis is on the deployment of less carbon intensive and more sustainable electricity sources due to climate effects, cost and air quality issues. The penetration of distributed generation resources (wind power, photovoltaic, fuel cells, biomass, small hydro plants, tidal \& geothermal etc) in distribution grid is increasing as a result. The deregulated electric industry provides the economic opportunities to the investors and many potential benefits for utilities (peak shaving, reduction in losses, transmission line cost, and better utilization of asset etc.) which further encourage the trend [1], [2].

Although there always exist important regulatory and business issues affecting the integration of DGs in to the grid but technical guidelines and standards are often considered as the critical factors affecting the development of new installations and ensuring the secure and reliable operation of the power system. The major technical and financial aspects like network capacity, slow and large voltage variations (flickering), harmonics emission, national and international safety rules, tariff structure review and network benefit of DGs have to be taken care of while dealing with the interconnection of a DG unit in to the grid. The interconnection criteria and procedures are based on the extensive set of IEC power quality standards. IEEE has also come up with a uniform technical standard IEEE - P1547 STD draft 07 for the interconnection of DGs with the grid [3], [4].

The most spread generation alternatives are mini-hydro, wind generation, co-generation in industry and small independent power generators (diesel, gas and biomass). Among the nonrenewable energy options considered, diesel engines are prevalent in India. However wind energy is growing significantly because of supportive policy environment, its low operating cost and cleaner source of energy with current global installed capacity of 74 GW which is expected to reach $160 \mathrm{GW}$ by 2010 . India stands at fourth place with installed capacity of $7 \mathrm{GW}$ after Germany, Spain and USA with $21 \mathrm{GW}, 12 \mathrm{GW}$ and $11.5 \mathrm{GW}$ of installed capacity respectively. 
The estimated wind power potential in India is more than $50 \mathrm{GW}$. The leading states in wind power potential in India are Gujarat, Andhra Pradesh, Karnataka, MP, Rajasthan, Tamil Nadu, Orissa and Kerala with potential of 9675 MW, 8275 MW, 6620 MW, 5500 MW, 5400 MW, 3050 MW, 1700 MW \& 875 MW respectively. NEG-MICON India Chennai, GE Wind Energy INDIA Bangalore, Elecon Engineering Co. Ltd Gujarat, Suzlon Energy Ltd etc are some of the top manufacturers of wind turbine in India. The ministry of new and Renewable Energy (MNRE) sources takes care of wind power development work on India. By 2012 the target is to achieve $10 \%$ of the power generation from renewable energy sources out of which 50 percent will come from wind power as estimated by center for wind energy technology (CWET) an R\&D institution of MNRE. The India's geographical location also has several advantages for the extensive use of the renewable energy sources [5], [6]. Wind power is going through rapid development. It is among the fastest growing power sources in the world and supplying significant shares of energy in large regions. However wind generation, in particular, has placed new challenges on the system operation and planning, because of the un-dispatchable nature of wind, the difficulty in forecasting, and the impossibility of storing it. Thus wind power integration in to the power system is now an issue in order to optimize the resource utilization and to continue the high rate of installation of wind generating capacity, which is necessary so as to achieve the goals of sustainability and security of the supply.

The main technical challenges associated with wind power integration include effects of wind power on the power system, the power system operating cost, power quality, power imbalances, power system dynamics and impacts on transmission planning. As the penetration of wind power increases i.e. above $20 \%$, the impact on the power system will also be higher. The emergence of wind and other DGs is coupled with the restructuring of the power sector and market orientation it received in recent years. This has opened new business opportunities to private investors, non-institutional, in supplying to the grid, resulting in a new inflow of capital to the sector. This has also presented new problems to an industry that was used to a tight control of their supply system. Now not only did planning become a difficult exercise, because the existence and location of new power plants became uncertain and dependent on the decision of third parties but also the operation was confronted with new degrees of uncertainty, not only as a result of private operators but also as a function of wind unpredictability. The requirements of power system with wind power, along with technical and economic challenges posed by it for reliable and economical operation and its solutions were proposed [7], [8], [9]. It's always advisable to operate wind power with any other generation mix to cater to its uncertainty. The technical, environmental effects and economical impacts of the wind integration with other generation mixtures were studied through a power balance model, which reveals rise in operational cost in case of 100 percent penetration of wind power but reduced the system wise emission abatement costs [10].

\section{Issues Related to Allocation of Reserves in System with Significant Wind Penetration}

Among the most common concerns while wind power integration, the very first concern is varying amounts of wind generation which tends to increase the need of ancillary services as the wind penetration increases into the system. Therefore, its large scale integration into the electric power system poses challenges to power system operators and planners. In short term, the variations in wind power affects the power system operation which includes allocation and use of extra reserves as well as cyclic losses of conventional power plants, transmission and distribution network impacts. In large system, the reserve requirements of different loads and wind power interact and partly compensate for each other. The variability introduced by the wind power will not be significant in case the variations are of same order as the variability of random behavior of the electricity consumers. The estimates for increased reserve requirement have resulted in a very small impact on time scale of seconds and minutes. However on the time scale of $15 \mathrm{~min}-1 \mathrm{~h}$, the estimated increase in the reserve requirement is of the order of $2-10 \%$ of installed wind power capacity, when the penetration level of wind is $10 \%$. Reserve services are the services required for the control of system frequency within certain bounds in the presence of these events. The primary reserves (within 10 seconds) are necessary in order to enable the system to intercept runaway frequency after an unexpected disturbance and are typically provided by spinning units within a very short time range. The importance is to estimate the required level of spinning and non spinning reserve in a power system with a high penetration of

IJEEI Vol. 4, No. 1, March 2016: 1-13 
wind power. The classic approach for the determination of the necessary primary frequency control services is based on off-line stability analysis of selected extreme conditions. This approach does not take in consideration the varying behavior of the demand and the dynamic characteristics of the generation response [11].

In [12] the author considers wind speed and load forecasts errors and ramp rates of conventional thermal units to determine system reserve margins in the wind-hydro-thermal interconnected Swedish electricity system. Consideration is given to the correlation of wind farm forecasts within a region and between different regions and links the reserve levels to a probability of too low a frequency due to load and wind fluctuations. In many systems, the amount of reserve carried at any time is just enough to cater for the loss of the largest in-feed. Although there is some uncertainty due to load forecast errors, system operators are familiar with this and can generally manage it. This approach does not guarantee a secure system at all times, but rather assumes any loss of generation greater than the largest infeed is so infrequent that it is deemed unnecessary to carry extra reserve all year round. When such an event does occur the system will have to shed some load. This simple approach to quantifying reserve needs has proven successful in many systems all over the world. However, as wind power penetration grows, there are concerns that the uncertain nature of wind power output will mean that amounts larger than the largest in-feed are lost more frequently as significant un-forecasted wind variations may coincide with large generator trips. A new probabilistic approach to quantify reserve demand was proposed [13] considering the generator outage rate; load and wind power forecast errors. The calculation for reserve level required at each hour was related with the reliability of the system assuming that average risk of load shedding as a result of the above factors remains same for all hours. In [14] the authors have suggested scheduling and pricing energy and reserves (primary, secondary and tertiary) simultaneously as these services are in fact strongly interrelated. The simultaneous operation will not only result the uniform prices for these services but also averts the need of ad-hoc operator, uneconomical out of merit operation, start-up of extra unit and unnecessary load shedding.

With the liberalization of the energy market and the associated unbundling of the formerly vertically integrated utilities, the transmission system operators (TSOs) are forced to introduce new functions in managing the system. A new division of the energy market structures is the ancillary services market, defined as the market of those services necessary to support the transmission of electric power from producer to purchaser. Ancillary services normally include voltage support, black start capability, automatic gain control (AGC), and reserves with varying levels of response times, etc. Using these services, the TSO must be able to maintain the system in a secure operating state in the most economic way. An economic load dispatch algorithm is proposed for getting generation schedule and primary spinning reserves which includes security margin as constraints extracted from different contingencies conditions [15]. Few other techniques using energy functions and artificial intelligence were also applied. However effect of response time of the offered reserves from generating units was not dealt properly. A hybrid deterministic -probabilistic approach to reliability constrained market clearing with unit commitment was used considering loss of load probability and expected load not served as upper bound criteria for reserve calculation [16]. However it was only a single-period market-clearing model and multi period model is required with simplification in hybrid metrics formation.

It has been suggested from previous work that the energy and reserve should be scheduled and priced simultaneously. The level of the reserve needed can be lowered in case the scheduling of reserve is done incorporating stochastic behavior of wind in the formulation of the problem. To obtain the economically optimal level of spinning and non-spinning reserves and their costs a two stage stochastic programming [53] market clearing model spanning a daily time horizon has been proposed. The structuring of two stage stochastic process is justified by the fact that electricity market must be cleared well in advance than the uncertainty associated with the wind power is realized. It takes in to account the networks constraints and the costs of lost load and wind spillage. Reserve requirement is driven by the trade-off between the value of lost load and energy and reserve offers [17]. In [18] author has used the concept of stochastic securities so as to improve the systemic scheduling of the reserves. This helps in minimizing costs of preventive measures through unit commitment, generation and load dispatch as well as reserve scheduling and post-disturbance corrective security actions. 
In the stochastic process modeling only the stochastic behavior of wind power is considered and the demand uncertainty and generation failures have been ignored. It needs to be incorporated along with stochastic security issues to achieve result accuracy in addition to precise modeling of the spatial and temporal correlations of wind related magnitudes. This proposed methodology can also be extended to reliability related issues such as the impact of increasing wind power penetration on loss of load expectation.

\section{Impacts of Wind Penetration on Power System Dispatch and its Cost: Unit Commitment Problem}

The second major concern with wind power is its impacts on electric power system operating costs. We know that wind speeds cannot be predicted with high accuracy over daily periods, and the wind often fluctuates from minute to minute and hour to hour. Consequently, electric utility system planners and operators are concerned that variations in wind plant output may increase the operating costs of the system. This concern arises because the system must maintain balance between the aggregate demand for electric power and the total power generated by all power plants feeding the system. This is a highly sophisticated task that utility operators and automatic controls perform routinely, based on well-known operating characteristics for conventional power plants, sophisticated decision-support algorithms and systems, and a great deal of experience accumulated over many years.

An increase in variable generation on an electricity system may require the system operator to alter how conventional generation is dispatched since wind generation may receive priority dispatch. As such, conventional generation may be obliged to operate at different operating levels in order to be available to ramp up or down to accommodate the inherent variability of the wind generation. There may also be an increase in the number of start-ups and shut-downs of other units as system operators attempt to coordinate the following of the fluctuating load throughout the day and the variable output of the wind generation. The numbers of investigations have been done to find the impacts of wind power on operating costs of electric power system. Utilities system with different generating resources mixes were investigated with different analytical techniques. The common element of study is to find the cost of ancillary services necessary to accommodate a wind plant on a utility system. There are typically three time scales of interest, which correspond to the operation of the utility system and the structure of the competitive electricity markets [7]:

1. Unit-commitment (UC) horizon of 1 day to 1 week with $1 \mathrm{~h}$ time increments,

2. Load-following horizons of $1 \mathrm{~h}$ with $5-10 \mathrm{~min}$ increments (intra-hour),

3. Regulation horizon of $1 \mathrm{~min}-1 \mathrm{~h}$ with $1-5 \mathrm{~s}$ increments.

Each of the time frames has special planning and operating requirements and costs. The unit commitment is the most common and the most important issue in power system operation and control. The problem becomes very complex with the penetration of wind power into the system. Number of studies has been carried out for optimal selection of on-line units and optimal output levels of committed units in the power system with various generation mixtures such as thermal-wind, hydro-wind, PV-wind and diesel-wind etc. The studies carried out used mostly the deterministic approach for analysis. However the stochastic behavior of wind should also be modeled. The additional reserves for wind power must be allocated to guarantee operational reliability and minimize associated cost. Assessment of wind power's impact on unit commitment and dispatch is, therefore, a fundamental issue when integrating more wind power into power system.

The unit commitment problem is commonly a non linear, large scale, mixed integer combinational problem. There can be large savings by improving unit scheduling so considerable attention have been given to develop efficient solutions. Various mathematical programming and heuristic based approaches such as: dynamic programming [11], neural networks, simulated annealing, evolutionary programming, genetic algorithm [19] and particle swarm optimization [20] based have been used to solve the UC problem. The methods proposed were however applied to the conventional generation most of the time.

Liu Yong and Shang Tao [21] solved economic dispatch problem incorporating wind plant with thermal units using genetic algorithm considering constraints like valve point effect, ramp rate limits etc and the effect of wind generation on net operating cost was demonstrated. But it was for a perfect wind power prediction which is far from the real operation. A simulation

IJEEI Vol. 4, No. 1, March 2016: 1-13 
method, based on time series for dealing with volatile wind generation, applied the security constrained economic dispatch algorithm to investigate the impact of wind power on thermal generation unit commitment and dispatch [22]. Another security constrained unit commitment unit commitment algorithm was put forward where re-dispatching of non-wind units was done during wind volatility. The reserves option was not considered as system may not have enough generation ramping capabilities at a given hour for supplying the allocated reserve when wind generation is not available in real time [23]. The unit commitment problem as mixed integer was solved [24] for an island of Ireland. The detailed analysis of the factors affecting the net benefits of wind penetration level were investigated, considering start-up costs, average ramping excursion and change in emissions of $\mathrm{SO}_{2}$ and $\mathrm{NO}_{x}$. One such problem formulation was done in [25] where reliability and emissions constraints were included in unit commitment and a cost of violation was added to the total operating cost. The effect of must run wind farms was also added to the problem.

The uncertainties in wind power forecast force the operators to change the schedule and that can result in high cost of operation. In order incorporate the stochastic nature of wind few Unit commitment models based on stochastic optimization were proposed which help in optimal day- ahead scheduling even under varying load conditions. To accommodate large variation of wind power and load, scenario reduction techniques using (Monte-Carlo simulation, PSO etc.) were used in stochastic optimization problem. The approaches have revealed that the solution of the UC problem through stochastic programming not only helps in minimizing cost but also involve lower risk in power system operation along with lesser reserve requirement [26], [27]. In [28] a long term security-constrained stochastic unit commitment (SCUC) model is described, which models unit and transmission line outages, as well as load forecasting inaccuracies.

A multistage stochastic model for optimal operation of wind farm, pumped storage and thermal power plants was used to solve unit commitment under wind and demand uncertainties. Wind power and demand were taken as two independent processes and scenario generated were reduced with adaptive PSO. The solution gives robust solution for the day ahead scheduling [29]. The enforcement of reserve requirement in scenario generation is also very crucial to counter the whole spectrum of uncertainty and leads to reduced costs and increased reliability and build confidence in unit commitment decision by the operators. It's very important to include all the sources of uncertainties like wind power error, demand variation, generator outage and reactive power requirement in scenario generation to obtain better solution than the deterministic one [30]. While modeling this type of cases care should be taken to keep the computation time minimum possible. WILMAR project [31] developed a stochastic scheduling tool to examine impact of variability of wind in energy market. It gave the concept of rolling planning that means the system is rescheduled as more precise wind and load forecasts are available.

In [32] authors have gone for more frequent planning (i.e. Impact of modeling the uncertainty of wind in different timescales) and it has helped in reduction in the operating cost, lesser reserve requirement and increases the performance of the schedules.

The problem in power system operation with wind is not only the stochastic nature of wind but also many other constraints such as generation limits, forbidden zones, ramping limits, line limits and ancillary services requirement. Hence to obtain the schedule real time pricing (RTP) can play an important role along with stochastic programming. The day-ahead unit commitment was solved using an hourly time-step for the commitment and dispatch variables, day-ahead forecast of loads, transmission capacities and availability of wind generation. It was demonstrated that RTP provides maximum gains when only commercial and industrial customers were charged by it and residential customers were charged at fixed rate [33]. There was also an attempt to solve define commitment of wind turbines and their active and reactive power outputs following a request from wind park dispatch center [34].

\section{Operation and Control of Power System in Liberalized Electricity Market: Trading Issues}

Most of the countries of the world have agreed to generate energy by renewable sources, i.e., mainly by biomass, hydro power, wind energy and solar energy. In addition, with the implementation of the Kyoto protocol, a number of countries are liberalizing their electricity 
industry. The cornerstone in liberalization is the opening of the electricity markets for trade, both within the country and among countries. To generate efficient competition, unbundling of the power industry might be necessary: to split existing companies into independent ones for generation, transmission and distribution of electricity. Finally, in order to handle the dispatch of electricity, an independent systems operator is needed, and establishing a power exchange might facilitate and increase transparency in trading. The European countries have made it mandatory to have common rules for electricity market, right to access to the transmission and distribution grids of each others and introduced the concept of free trade.

A number of countries already have or are in the transition phase of liberalizing their electricity industry. Electricity exchange markets are being developed to facilitate electricity trade and now exist in several countries; among these are Germany, Netherlands, England, Norway, Sweden, Finland, Spain and Denmark. How wind power is to be integrated into the competitive electricity market is still an open question. At present, most renewable energy technologies are not economically competitive to conventional power producing plants. Thus, it can be expected that this will halt the development of new renewable capacity if renewables must compete on pure market conditions [31].

In Indian Electricity Act 2003, the emphasis is on development of a market based regime in Indian power sector through competition in which setting up of state regulatory commissions are mandatory. Trading has been given recognition and model is being shifted from single buyer model to multi buyer model. The operation and control of restructured electricity market put many technical and financial challenges than conventional monopolistic market. This is because of the involvement of large entities, their different contractual obligation separation of primary and ancillary services, and varying models of market management. The technical challenges include congestion management, market power, price volatility and ancillary services [35].

There are some standard electricity markets such as Nordic, Spanish, Ontario, German, England etc. The common market structure included in planning model is day ahead Market, Intraday market and ancillary service market etc. The processes in the production market are as per the sequence given below. Most of the transactions are carried out in the daily market. Then technical constraints are resolved by the system operators. Sometimes this may be through fresh bids for sales and purchase. The intra-day market is an adjustment market i.e. opens to generation units, distributors resellers etc. The purpose of the ancillary services and deviation management is to make sure that power is supplied under established condition of quality, reliability and security that, generation and demand are balanced.

The electricity markets worldwide are being reformed and regulatory policies have been characterized by making power industry more competitive in nature both at wholesale and at retail levels. Thus trading of power in the competitive market has to be designed carefully as any deviation from the committed generation will invite penalties thereby reducing value of energy revenue substantially. In addition optimal commercial operation of a wind farm may have a significant impact on the technical requirements for managing the real time balance of supply and demand of the power system.

In order to determine an optimum level of energy to be contracted a method using Markov probabilities has been proposed which minimizes the imbalance cost [36]. The wind power producers choose a bidding strategy with the aim of minimizing expected costs of imbalances by formulating a single period stochastic optimization problem which envisages the large number of possible scenarios of wind power production and imbalance costs [37]. Optimal bidding procedures for power producers in markets such as day-ahead, AGC and balancing have been devised using stochastic programming taking various risks of the market in to account. The wind producers' capability as price-maker in balancing market was used for profit maximization [38]. Within an electricity market framework, [39] models the day-ahead market in detail for a multi reservoir hydro power system coordinated with wind farm. The congestion also has an effect on bidding strategies as well as market clearing price. An electric power market modelled as oligopoly market and cournot quantity model is applied for bidding problem [40]. Another algorithm was developed for optimal bidding and scheduling with risk management using Lagrangian and stochastic dynamic programming whereby they obtain hourly offer curves for both energy and reserve markets [41]. A two stage stochastic optimization problem was introduced in a model giving optimal bids that should be submitted to day-ahead market. The model also introduces non-anticipatively criterion which helps in balancing uncertainty about

IJEEI Vol. 4, No. 1, March 2016: 1-13 
market prices and wind generation. The model also provides idea about the investment and optimal size of the pumped storage tank [42].

Though there has been considerable improvement in wind-energy conversion system, yet the power output from these systems is strongly conditioned by the variable characteristics of wind resources. Thus dispatch is rather difficult to predict and control of active powergeneration is required. The output controllability of the wind parks is being improved so as to facilitate the interaction of with energy power market. In [43] authors used the wind-small hydro to identify the best combined daily operation. The hydro was used to make up generation during low wind speeds and during congestion and low load conditions it was used to store the water through pumps. The effect of daily price variation, imbalance price spread and balancing market in the value of wind energy in hybrid system is formulated in [44], where optimal dispatch for electrical energy storage facility with wind farm is obtained.

The combination of wind with thermal generation to tackle volatility of wind generation for a secure economic dispatch was investigated by [22] which help in designing profitable strategies for the power market operation. Wang et al. have presented a security constrained unit commitment algorithm which takes in to account the intermittency and volatility of wind power generation. The proposed algorithm can be used for the operation planning in the dayahead as well as the long term planning of wind units in a constrained hybrid system including thermal power [23]. Simulation studies for integration of wind in deregulated power system have been studied with joint market model (JMM) a planning tool, while taking in to account the dayahead market and regulating power market. Stepwise power flow model was also studied which simulates the frequency deviation and power balancing within the hour. However allocation of regulating power has not been done dynamically and it should include congestion and forecast error as well [45]. The wind power is preferably coordinated with any other system which has got lesser start up cost of power plants and high ramp rate such as hydro power plants (HPP). In [46] the coordination is applied to minimize wind farm imbalances cost. The coordination with hydro power plants is employed only on the intraday market. Spot market and imbalances penalties are treated as deterministic. The transmission constraints are not considered in the planning.

A combined operation strategy and a combined bidding strategy have been studied in coordinated planning of wind with HPPs to maximize the revenue from combined operation overcoming the imbalance penalties in on the pool based market [47]. The paper however does not include the congestion problem due to wind and best bid can be ensured only if there is provision of reserve margin for all wind deviations. A day ahead planning algorithm is presented for a multi-reservoir hydropower system coordinated with wind power. The coordination applies to real situation where problems like congestions, uncertainty of wind power forecasts [48] and power market prices [49] have been considered [50]. To make the informed decisions in future markets of electrical energy, power utilities are being models through multistage stochastic programming. The set of scenarios are used to model multivariable random data processes such as electrical load, stream flow of hydro units, fuel and electricity prices etc. [51] [52]. The hybrid systems with low start ups time and cost should also be combined along with hydro to make them suitable to competitive electricity market operation.

Another major issue with the wind power generation and its interaction with grid is its impact on during power network disturbances. During disturbances wind farms have to be disconnected and loss of such a considerable part of power production (wind constitute in some regions) due to disturbances cannot be accepted [59]. In [60] author has summarized and investigated impact of various issues which pose technical challenge in integration such as using Doubly Fed Induction Generator (DFIG) instead of simple induction generator and reactive power requirement during fault, line trip, load disconnection and generation outages. It was found that focus should be on variable speed generator as fixed speed machine with capacitive compensation during faults may lose synchronism moreover voltage profile required at point of common coupling also is better with DFIG making it suitable for interconnection. Another study [61] comparing the performances of two generators suggested proper coordination between control and protection of wind turbine to minimize trips. VAR compensation or reserve requirement is needed to ensure stable operation. The possibility of interconnection between wind and HVDC line should be explored.

Wind turbines require large reactive power during contingencies failing which wind farms (WFs) may have to be disconnected. It's important to study and model the optimal 
reactive power flow in system with wind integration for secure operation [62]. Wind power generation also affects the power system oscillations; a qualitative analysis on its impacts revealed that constant speed generators are better in damping the oscillations than variable speed generators [63]. The minute-to-minute variations (wind die out, wind rise, wind lull, wind gusts) of wind power was studied through simulation models on a system having power plants, WFs, transmission lines, loads and AGC. The time delay in AGC decides the system dynamics and demand ramps are more severe than WF output ramps. The wind and thermal generators were operated together and it was concluded that thermal generators easily absorbed the frequency variations caused by the wind deviations [64]. The wind turbines were also found suitable to provide temporary primary frequency control in the hydro dominated areas. The initial surges of hydro generators require extra active power support from a wind farm to arrest the initial frequency fall [65]. Detailed modelling is required to investigate the impacts in power system comprising large generation mix.

With the inclusion of large wind sources in to the system the conventional power sources will be retired and there can be insufficient kinetic energy from the plants to support the system frequency [66]. Hence the primary reserve used to support frequency against drop in the event of faults or demand change may hamper the performance of the power system. As wind turbines are asynchronously coupled to the system hence frequency threshold detector and power electronics control should be fast enough to discharge the kinetic energy storage. The need is to study the coordination of timing and size of the kinetic energy discharge with the characteristics of conventional plants is required. DFIG can be used as it provides support to system frequency. Doubly fed induction generator (DFIG)-based wind turbines have been the favoured alternative due to their ability to provide the benefits of variable-speed operation costeffectively. The applied power electronic converters are generally sized only for $20 \%-35 \%$ of the stator power depending on the slip range and reactive power requirements. Fast control over electrical torque (hence active power) and reactive power offer superior performance concerning system stability during disturbances. As the penetration of the wind turbines into the power system increases, their contribution to ancillary services (e.g., voltage and frequency control) becomes more significant and necessary [67].

\section{Combined Operation of Wind and Hydro:}

The wind generation companies and hydro generation companies can be operated together for revenue maximization. The high penalty due to wind imbalances will require hydro producers to cover for the wind producers. The cover will also depend upon future value of water and cover is provided only if there is high penalty imposed, i.e. revenue to be paid for imbalances is more as compared to revenue that would be generated by hydro by storing water. The revenue and hydro power generations are obtained for combined operation taking single auction and several auctions provisions in wind market Table 4. The optimal schedule for hydro power generation is given in the Table 5 below. The graphical view of the hydro generation and water levels for the three intervals under study is given in Figure 3 below.

Table 4. Revenue in Euro generated by combined operation of wind hydro

\begin{tabular}{lllll}
\hline & Min accuracy & Ave Accuracy & Max Accuracy & Persistence \\
\hline 1 Auction & 567520.905 & 568611.621 & 568096.857 & 535852.51 \\
Several Auction & 567699.358 & 537931.66 & 567930.457 & \\
\hline
\end{tabular}




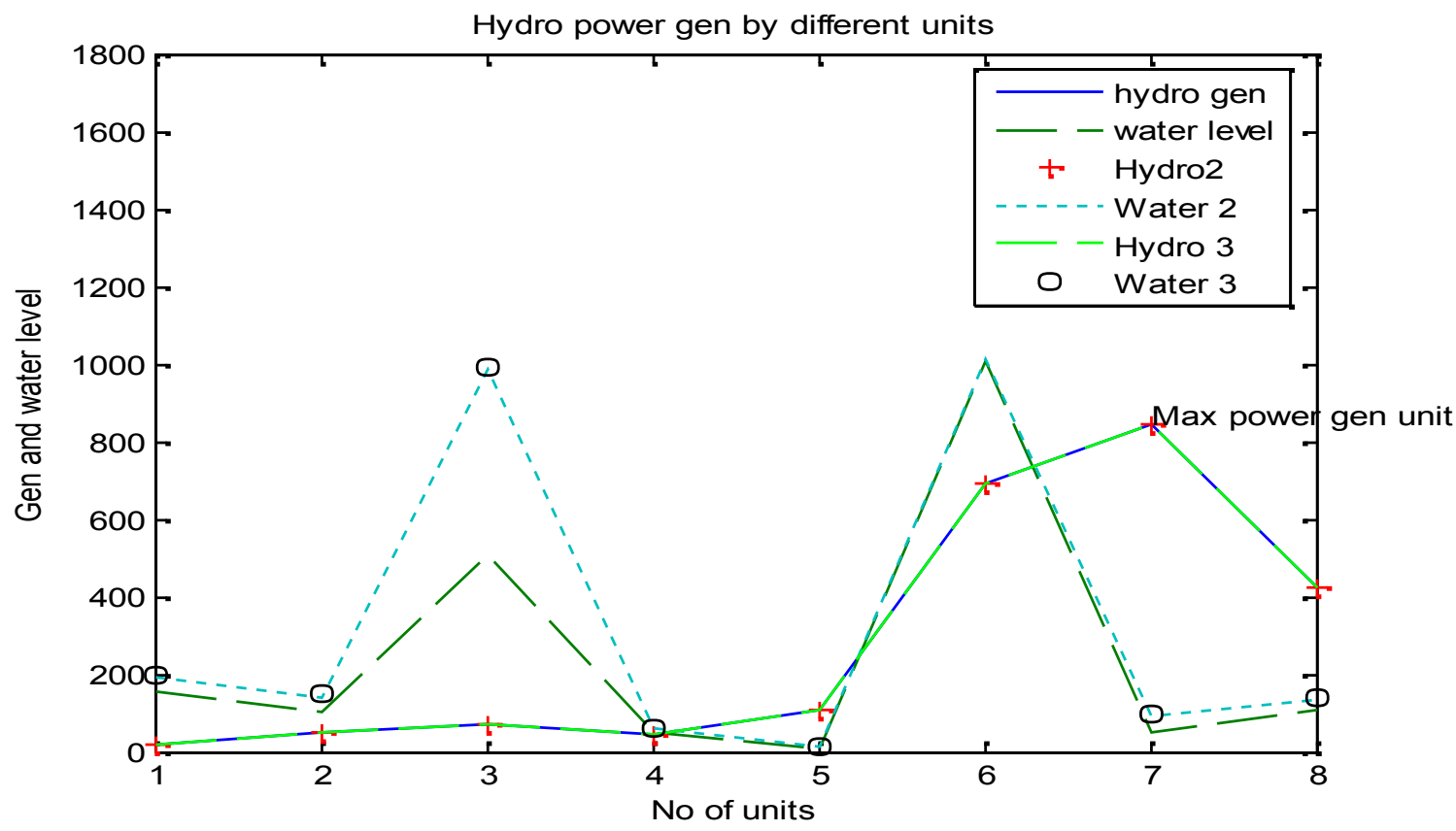

Figure 3. Graph showing Hydro generation and water level in different interval for combined operation

The penalty has huge impact on the revenue. The revenue generated with different values of penalty with maximum accuracy wind forecasting for single auction, several auction and persistence have been given in the Figure 4 below. It also gives the comparison of the revenues generated by accuracy level of wind generation. Figure 5 shows the increase in the profit due to combined operation for different values of penalties. The full cover from hydro power producers to wind deviation will be provided only if revenue generated is lesser by storing water (depends upon future value of the water taken as 60 euro as used in model).

Table 5. Hydro power generation for three different intervals under study

\begin{tabular}{lllllll}
\hline Unit No & $\begin{array}{l}\text { HGen } \mathbf{1} \\
\mathbf{M W}\end{array}$ & $\begin{array}{l}\text { Water Level in } \\
\mathbf{1} \mathbf{H m}^{\mathbf{3}}\end{array}$ & $\begin{array}{l}\text { HGen2 } \\
\mathbf{M W}\end{array}$ & $\begin{array}{l}\text { Water Level in } \\
\mathbf{2} \mathbf{H m}^{\mathbf{3}}\end{array}$ & $\begin{array}{l}\text { HGen3 in } \\
\mathbf{M W}\end{array}$ & $\begin{array}{l}\text { Water Level in } \\
\mathbf{3 ~ H}^{\mathbf{3}}\end{array}$ \\
\hline 1 & 20.94 & 152.99 & 20.74 & 192.99 & 20.94 & 199.97 \\
2 & 48.70 & 100.9824 & 48.70 & 138.1460 & 48.760 & 148.9824 \\
3 & 69.9000 & 505.9554 & 69.9000 & 985.96 & 69.9000 & 991.9554 \\
4 & 42.1165 & 51.9371 & 42.1165 & 59.94 & 42.1165 & 59.9371 \\
5 & 108.5800 & 9.9393 & 108.5800 & 11.94 & 108.5800 & 11.94 \\
6 & 692.3850 & 1009.9420 & 692.3850 & 1012.50 & 692.3850 & 1012.9420 \\
7 & 846.0600 & 49.73 & 846.0600 & 89.9104 & 846.0600 & 94.9104 \\
8 & 423.1520 & 109.048 & 423.1520 & 133.9048 & 423.1520 & 140.9048 \\
\hline
\end{tabular}




\section{Revenue for different Forecast and Penalties}
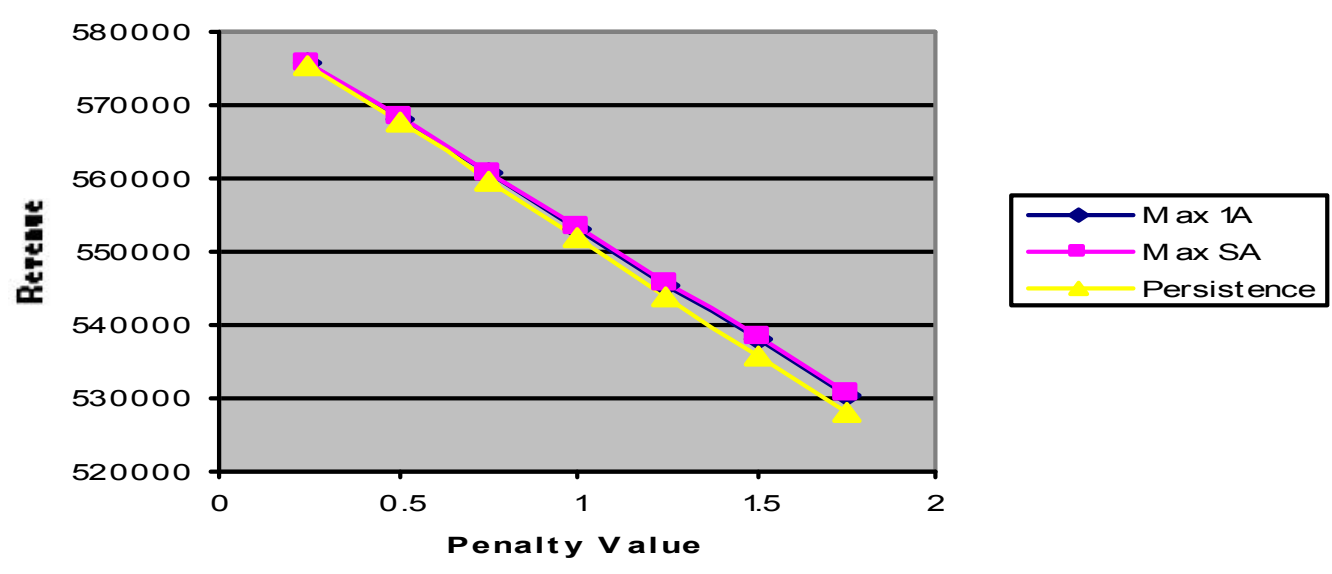

Figure 4. Comparison of revenue for max accuracy of wind prediction and different penalties imposed

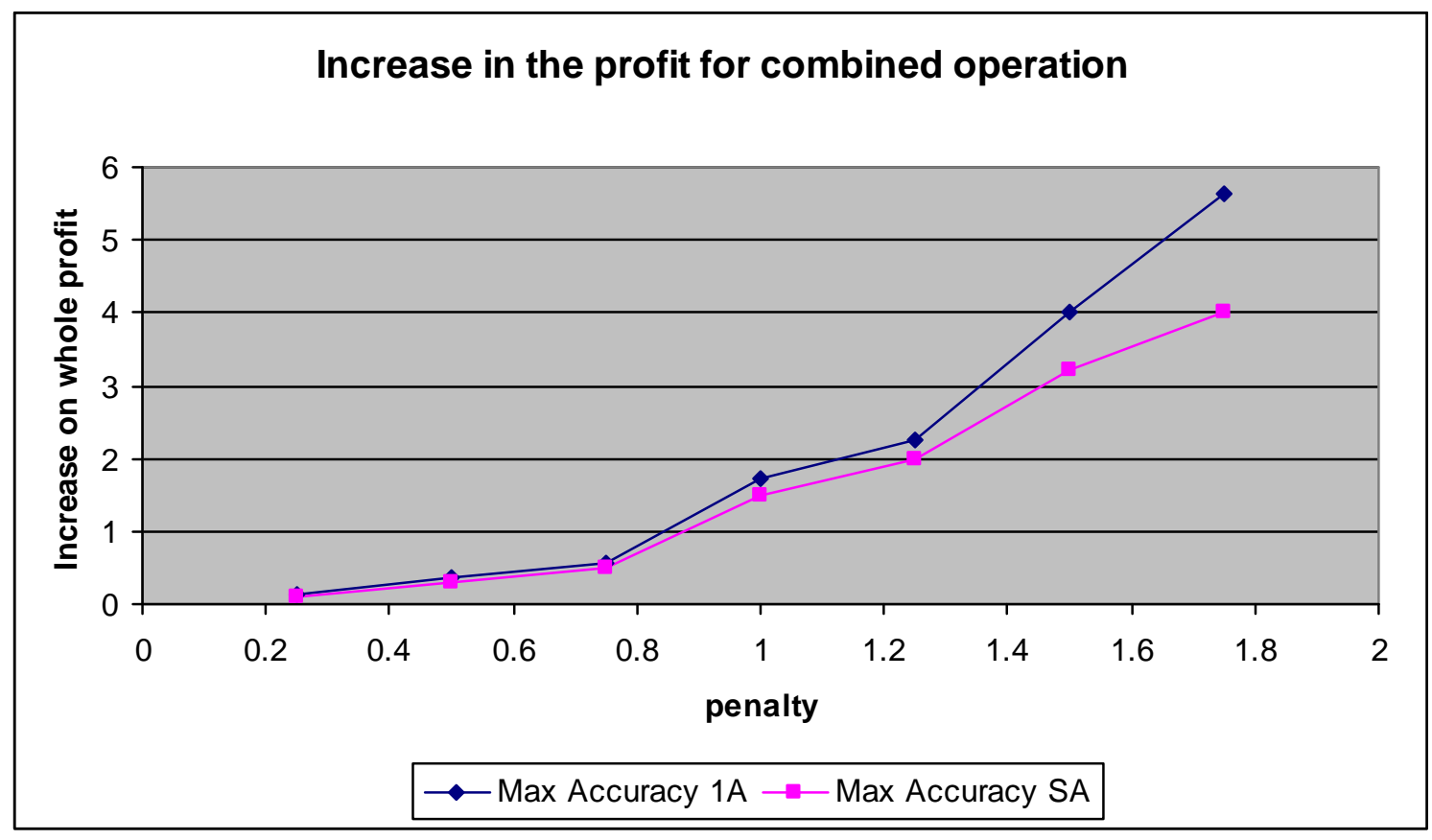

Figure 5. Change in revenue for different schedule markets

\section{Conclusion}

The hydro power is always considered as the best option to complement the wind power generation. To cater to the uncertainty of wind power, sources with small start up time as well cost, along with the high ramp capability are preferred. The review revealed that forecasting does have an effect on the bidding strategy and hydro power can be the best option to cover the power imbalances due to wind and hence increase the revenue. This paper motivates for development of a model for hybrid system with wind to investigate the combined operation of wind with different sources to cater to wind's stochastic nature for imbalance minimization and optimal operation. The unit commitment or dispatch problems with wind power under demand 
and generation uncertainty with optimization techniques or stochastic programming. An overview on reserve modelling in for power system with wind power to allocate and quantify the reserves (spinning and non-spinning) amount for the power system for secure and economical operation and to investigate the effects of load variations and congestion on wind power generation and reserve requirements has been described in this paper. Development of model for trading power in competitive electricity market and development of strategies for trading in electricity markets (wind energy and reserves markets) to investigate the effects of real time pricing tariffs on electricity market operation has been suggested in this paper. Dynamic modelling related studies to investigate the wind generator's kinetic energy for primary frequency support using simulink and simulation studies on doubly fed induction generator (DFIG) to study its capability during small disturbances / fluctuations on power system have been described.

\section{Acknowledgements}

Authors are grateful to Mewar University, Chittorgarh, Rajasthan (India), Inderaprastha Engineering College, Ghaziabad (Uttar Pradesh), India and Electrical Engineering Department, Institute of Technology, Banaras Hindu University, Varanasi (India) for providing necessary facilities and peaceful environment to complete this research article. Authors present humble thanks to newly born kids: Sujata Chaubey and Siddhant Vardhan for providing emotional happiness and encouragement to complete this manuscript in its present shape.

\section{References}

[1] T Ackermann, G Andersson and L Söder. "Distributed generation: a definition". Electric Power System Research. 2001; 57: 195-204.

[2] W El-Khattam and MMA Salama. "Distributed generation technologies, definitions and benefits". Electric Power System Research. 2004; 71: 119-128.

[3] P Dondi, D Bayoumi, C Haederli, D Julian and M Suter. "Network integration of distributed power generation". Electric Power System Research. 2002; 106: 1-9.

[4] S Papathanassiou. "A technical evaluation framework for the connection of DG to the distribution network". Electric Power System Research. 2007; 77: 24-34.

[5] MC Mabel, E Fernandez. "Growth and future of wind energy in India". Renewable and Sustainable Energy Reviews. 2008; 12: 1745-1757.

[6] N Golait et al. "Wind electric power in the world and perspectives of its development in India". Renewable and Sustainable Energy Reviews. 2007: doi: 10.1016 / j.resr.2007.07.005

[7] PS Georgilakis. "Technical challenges associated with the integration of wind power in to power systems". Renewable and Sustainable Energy Reviews. 2008; 12: 852-863.

[8] H Holttien and R Hirvonen. "Power System Requirements for Wind Power". Chapter 8 in Wind Power in Power System Ed. by T. Ackermann, John Wiley \& Sons Ltd. 2005: 144-167.

[9] V Miranda. "Wind Power, Distributed Generations: New Challenges, New Solutions". Turk Journal of Electrical Engineering. 2006; 14(3): 455-473.

[10] JD Maddaloni, AM Rowe and GC Kooten. "Wind integration in to various generation mixtures". Renewable Energy. 2009; 34: 807-814.

[11] AJ Wood and BF Wollenberg. Power Generation, Operation, and Control. New York: Wiley. 1996.

[12] L Soder. "Reserve margin planning in a wind-hydro-thermal power system". IEEE Transactions on Power system. 1993; 8(2): 564-571.

[13] R Doherty, MO Malley. "A new approach to quantify reserve demand in systems with significant installed wind capacity". IEEE Transactions on Power Systems. 2005; 20(2): 587-595.

[14] FD Galaina et al. "Scheduling and pricing of Coupled energy and primary, Secondary, and Tertiary Reserves". Proceedings of the IEEE. 2005; 93(11): 1970-1983.

[15] KA Papadogiannis and ND Hatziargyriou. "Optimal allocation of primary reserve services in energy markets". IEEE Transactions on Power Systems. 2004; 19(1): 652-659.

[16] F Bouffard and FD Galiana. "An Electricity Market with probabilistic spinning reserve criterion". IEEE Transactions on Power Systems. 2004; 19(1): 300-307.

[17] JM Morales, AJ Conejo and JP Ruiz. "Economic valuation of reserves in power systems with high penetration of wind power". IEEE Transactions on Power Systems. 2004; 24(2): 900-910.

[18] F Bouffard and FD Galiana. "Stochastic security for operations planning with significant wind power generation". IEEE Transactions on Power Systems. 2008; 23(2): 306-316.

[19] SA Kazarlis, AG Bakirtzis and V Petridis. "A genetic algorithm solution to the unit commitment problem". IEEE Transactions on Power Systems. 1996; 11(1): 823-92. 
[20] P Sriyanyong and YH Song. "Unit commitment using particle swarm optimization combined with Lagrange Relaxation". IEEE PES General Meeting. 2005.

[21] L Yong and S Tao. "Economic dispatch of power system incorporating wind power plant". $8^{\text {th }}$ International Power Engineering Conference (IPEC 2007). 2007: 159-162.

[22] BC Ummels, M Gibescu and E Pelgrum. "Impacts of Wind Power on Thermal generation Unit Commitment and Dispatch". IEEE transactions on Energy conversion. 2007; 22(1): 44-51.

[23] J Wang, M Shahidehpour and Z Li. "Security constrained Unit Commitment with volatile wind power generation”. IEEE transactions on Power Systems. 2008; 23(3): 1319-1327.

[24] E Denny et al. "A quantitative analysis of the net benefits of grid integrated wind". IEEE PES GM. 2006: 1-8.

[25] SH Hosseini and E Abbasi. "Probabilistic Unit Commitment with wind farms considerations". IEEE PES GM. 2007.

[26] S Takriti, JR Birge and E Long. "A stochastic model for the unit commitment problem". IEEE Trans. Power Syst. 1996; 11: 1497-1508.

[27] VS Pappala, I Erlich and J Dobschinski. "A stochastic Model for the optimal operation of a wind thermal power system". IEEE transactions on Power Systems. 2009; 24(2): 940-950.

[28] L Wu, M Shahidehpour and T Li. "Stochastic security-constrained Unit Commitment". IEEE transactions on Power Systems. 2007; 22(2): 800-811.

[29] VS Pappala, I Erlich and SN Singh. "Unit commitment under wind power and demand uncertainties". IEEE, PES. 2008.

[30] PA Ruiz et al. "Uncertainty management in the unit commitment problem". IEEE transactions on Power Systems. 2009; 24(2): 642-651.

[31] Wind Power Integration in Liberalized Electricity Markets (Wilmar) Project. (Online), Available: www.wilmar.risoe.dk

[32] A Tuohy, P Meibom, E Denny and MO Malley. "Unit commitment for systems with significant wind penetration". IEEE transactions on Power Systems. 2009; 24(2): 592-601.

[33] R Sioshansi and W Short. "Evaluating the impacts of Real-Time Pricing on the Usage of Wind Generation". IEEE transactions on Power Systems. 2009; 24(2): 516-524.

[34] CF Moyano and JAP Lopes. "An optimization approach for wind turbine commitment and dispatch in a wind park". Electric Power System Research. 2008; doi:10.1016/j.espr.2008.05004

[35] P Bajpai and SN Singh. "An Electric Power Trading Model for Indian Electricity Market". Presented at IEEE PES Gen. Meet., Montreal. 2006.

[36] GN Bathurst, J Weatherill and G Strbac. "Trading wind generation in short term energy markets". IEEE Trans. Power System. 2002; 17(3): 782-789.

[37] J Matevosyan, L Soder. "Minimization of imbalance cost trading with wind power on the short-term power market". IEEE Transactions on Power Systems. 2006; 21(3): 1396-1404.

[38] MA Plazas, AJ Conejo, FJ Prieto. "Multimarket optimal bidding for a power producer". IEEE Transactions on Power Systems. 2005; 20(4): 2041-2050.

[39] A Baillo, M Ventosa, M Rivier and A Ramos. "Optimal offering strategies for generation companies operating in electricity spot markets". IEEE Trans. Power Syst. 2004; 19(2): 745-753.

[40] T Peng and K Tomsovic. "Congestion influence on Bidding Strategies in an Electricity Market". IEEE Trans. Power Syst. 2003; 18(3): 1054-1061.

[41] E Ni, PB Luh, S Rourke. "Optimal integrated generation bidding and scheduling with risk management under a deregulated power market". IEEE Transactions on Power Systems. 2004; 19(1): 600-609.

[42] JG Gonzalez, R Muela, L Santos and AM Gonzalez. "Stochastic joint optimization of wind generation and pumped-storage units in an electricity market". IEEE Transactions on Power Systems. 2008; 23(2): 460-468.

[43] ED Castronuovo and JAP Lopes. "On the optimization of the daily operation of a wind-hydro power plant". IEEE Trans. Power Syst. 2004; 19: 1599-1606.

[44] GN Bathurst, G Strbac. "Value of combining energy storage and wind in short-term energy and balancing markets". Electrical power System Research. 2003; 67: 1-8.

[45] P Sorensen, N Ian, M Peter and K Uhlen. "Simulations of wind power integration with complementary power system planning tools". Electrical Power System Research. 2008; 78: 1069-1079.

[46] JM Angarita, JG Usaola. "Combining hydro-generation and wind energy biddings and operation on electricity spot markets". Electric Power Systems Research. 2007; 77: 393-400.

[47] JL Angarita, J Usaola and JM Crespo. "Combined hydro-wind generation bids in a pool-based electricity market". Electric Power Systems Research. 2009; 79: 1038-1046.

[48] M Lei et al. "A review on the forecasting of wind speed and generated power". Renewable and Sustainable Energy Reviews. 2008; doi.10.1016./j.resr.2008.02.002.

[49] J Contreras, R Espinola, FJ Nogales and AJ Conejo. "ARIMA models to predict next day electricity prices". IEEE Transactions on Power Systems. 2003; 18(3): 1014-1019. 
[50] J Matevosyan, M Olsson and L Soder. "Hydropower planning coordinated with wind power in areas with congestion problems for trading on the spot and the regulating market". Electric Power System Research. In Press.

[51] N Gröwe-Kuska, H Heitsch and W Römisch. "Scenario reduction and scenario tree construction for power management problems”. in Proc. IEEE Power Tech Conf. Bologna, Italy. 2003.

[52] JM Morela, AJ Conejo, S Pienda and M Carrian. "Scenario reduction for future market trading in electricity markets". IEEE Transactions on Power Systems. 2009; 24(2): 878-888.

[53] P Kall and SW Wallace. Stochastic Programming. Chichester, U.K.: Wiley. 1994.

[54] C Belanger, L Gagnon. "Adding wind energy to hydropower". Energy Policy. 2002; 30: 1279-84.

[55] R Cadenas, R Mota, I Gallegos and S Lopez. "Wind and hydro power plants as a hybrid system". Proceedings of Wind power, Washington DC. 2001

[56] A Conejo, JM Arroyo, J Contreras. "Self-scheduling of a hydro producer in a pool-based electricity market”. IEEE Trans. Power System. 2002; 17(4): 1265-1272.

[57] J Usaola, O Ravelo, I S'anchez, C Velasco, J Dom'inguez, MG Lobo, G Gonz'alez, F Soto, SIPREOLICO: a wind power prediction tool for the Spanish peninsular power system operation. in: CIGRE 40th General Session \& Exhibition, Paris, France. 2004.

[58] A Brooke, D Kendrick, A Meeraus, R Raman and RE Rosenthal. GAMS, a User's Guide. Washington, DC: GAMS Development Corporation. 1998.

[59] I Erlich and U Bachmann. "Grid code requirements concerning connection and operation of wind turbines in Germany". IEEE PES GM. 2005: 2230-2234.

[60] NR Ullah, T Thiringer and D Karlsson. "Operation of wind Energy Installations during Power Network Disturbances". IEEE PES. 2007: 1396-1400 GM.

[61] P Pourbeik, RJ Koessler, DL Dickmander and W Wong. "Integration of large Wind farms into Utility Grids (Part-2-performances Issues)". ABB Inc. 1-6.

[62] J Qiao, Y Min and Z Lu. "Optimal Reactive Power Flow in Wind Generation Integrated Power System". International conference on Power System technology. 2006.

[63] JG Slootweg and WL Kling. "The impacts of large scale wind power generation on power system oscillations". Electric Power Systems Research. 2003; 67: 9-20.

[64] H Banakar, C Luo and BT Ooi. "Impacts of wind power minute-to-minute variations on power system operation". IEEE Transactions on Power Systems. 2008; 23(1): 150-160.

[65] NR Ullah, T Thiringer and D Karlsson. "Temporary Primary Frequency Control support by Variable speed wind turbines- Potential and Applications". IEEE Transactions on Power Systems. 2008; 23(2): 601-612.

[66] P Keung, P Lei, H Banakar and BT Ooi. "Kinetic energy of wind -turbine generators for system frequency support". IEEE Transactions on Power Systems. 2009; 24(1): 279-287.

[67] M Kayikci and JV Milanovic. "Dynamic contribution of DFIG-based wind plants to system frequency Disturbances". IEEE Transactions on Power Systems. 2009; 24(2): 859-867. 